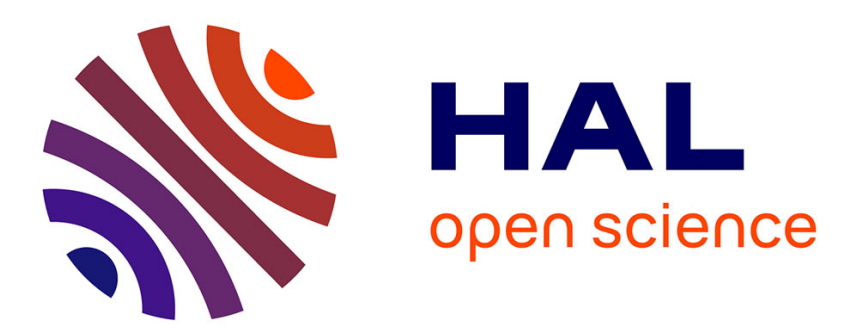

\title{
A Continuum of Interfaces to Engage Surgical Staff in Efficient Collaboration
}

Juliette Rambourg, Hélène Gaspard-Boulinc, Stéphane Conversy, Marc Garbey

\section{- To cite this version:}

Juliette Rambourg, Hélène Gaspard-Boulinc, Stéphane Conversy, Marc Garbey. A Continuum of Interfaces to Engage Surgical Staff in Efficient Collaboration. Journal of Medical Systems, 2019, 43 (7), 10.1007/s10916-019-1318-1 . hal-02132979

\section{HAL Id: hal-02132979 \\ https://hal-enac.archives-ouvertes.fr/hal-02132979}

Submitted on 3 Jun 2019

HAL is a multi-disciplinary open access archive for the deposit and dissemination of scientific research documents, whether they are published or not. The documents may come from teaching and research institutions in France or abroad, or from public or private research centers.
L'archive ouverte pluridisciplinaire HAL, est destinée au dépôt et à la diffusion de documents scientifiques de niveau recherche, publiés ou non, émanant des établissements d'enseignement et de recherche français ou étrangers, des laboratoires publics ou privés. 


\title{
A Continuum of Interfaces to Engage Surgical Staff in Efficient Collaboration
}

\author{
Juliette Rambourg1, 2 Hélène Gaspard-Boulinc, P.h.D ${ }^{2}$ Stéphane Conversy, P.h.D ${ }^{2}$ Marc Garbey, \\ P.h.D ${ }^{1}$ \\ ${ }^{1}$ Houston Methodist Hospital, Houston, TX, USA. \\ 2 ENAC - French University of Civil Aviation, Toulouse, France.
}

\begin{abstract}
Large hospital surgical suites must combine high quality of care with an efficient management of operations. However, the diversity of procedures, staff, and patients present important challenges for staff collaboration. The complexity of flows between tasks and places, such as interconnections between pre-operation, postoperation and intensive care units, led previous research to address these issues separately using checklists, scheduling, or specialized human-computer interfaces. Approaches to treat the surgical suite as a whole entity have not been explored yet. Here, we build upon a cyber-physical system comprising an electronic whiteboard and different sensors tracking the status of operating rooms to design a continuum of mobile and fixed, shared computer interfaces. The interfaces disseminate the information through different locations and devices and allow for its manipulation in order to foster appropriate collaboration on unforeseen events and decisions. We present our design rationale process, involving the different surgical suite users and stakeholders and report on the architecture of the system.
\end{abstract}

\section{Keywords}

Hospital; cyber-physical system; surgical suite; collaboration; surgical flow; perioperative activity; awareness; information mobility.

\section{Introduction}

Improving patient care quality is the main displayed motive of hospitals' computer systems, while important underlying reasons of successful stories depend on an efficient management of operations in terms of security, safety, costs, and revenue.

Considering the evolution of the Electronic Health Record (EHR) industry, Epic Company has an $80 \%$ market share [1] in the US. Key successes of the EHR are its capability to interconnect all the data of hospital systems and to serve as a collaborative tool between all the stakeholders. The EHR rigorously tracks cost, revenue, and patient care. The Epic software is a hospital information system, including the EHRs.

As revenues from Operating Rooms (OR) represent about 50\% of large hospitals' income [2-3], improving capacity by bringing a better management of the surgical flow benefits on all tables. However, designing systems to foster staff collaboration in this environment is challenging due to the heterogeneity of situations, patients, staff, and procedures. Many projects were carried out in this field to study staff collaboration and its support [4-6], but approaches to treat the surgical suite as a whole entity have not been explored yet.

Our hypothesis is that a successful Human Computer System to manage surgical flow must provide a continuum of interactive devices in order to engage all the users in sharing information and efficiently coordinating patient care within the surgical suites. Surgeons and Anesthesiologists are very mobile, and the surgical suite is interconnected with the pre-operation, OR, post-operation, and Intensive Care Unit (ICU) systems. Providing the right information at the right moment to the right person without delay or overload and letting him/her enter the interaction continuum to improve quality of care is the next frontier.

We present a study and a solution built upon a cyber-physical system, comprising an electronic whiteboard and multiple sensors tracking the ORs' status, with a continuum of mobile and fixed, shared computer interfaces. The interfaces' purpose is to foster an appropriate collaboration on unforeseen events and decisions. The system 
combines a theoretical counterpart that is a stochastic mathematical model of surgical flow using an AgentBased Model (ABM) like structure with social network background to simulate the daily clinical activity and take into account human behaviors [7].

Few cyber-physical system architectures have been offered for healthcare so far [8-9]. Only some examples of mobile technologies [10] are reported to be needed by the staff [11-12], or design-methods suggestions [13], or in-OR systems [14] have been reported but without a holistic integration of the different parts of the surgical suite - pre-operation, ORs, post-operation, ICUs, etc. Several issues result from this, an example of which is reported by Amir et al. [15] where the lack of communication means, including the whole care team and even for patients' families, happens most of all during transition phases. Transition phases occur numerous times in the surgical suite, including staff shifts and discussions with the family. Further, research directions and challenges involved in building MCPS (Medical Cyber-Physical Systems) are extensively discussed and described as by Lee et al. [8]. High Assurance Software, Interoperability, Context-Awareness, Autonomy, Security and Privacy and Certifiability are the most highlighted ones. Our study focus on improving the surgical team Context-Awareness.

An analogy between civil aviation and hospital health management has finely been highlighted by Kapur et al., Toff and Helmreich [16-18]. The members of our team come from both worlds and a focus of our research is to find out if the industry organization of civil aviation, its culture of safety and long-standing experience on designing human-computer interfaces, can be transferred to hospitals' surgical suite management systems. Civil aviation studies for Air Traffic Control (ATC) present shared specificities with the hospital surgical suite, such as safety/security management, cost-efficiency, emergency situations, and high team workload.

This paper summarizes our design method, involving the different surgical users and stakeholders, and report on the architecture of the system.

\section{Method}

The approach used is described starting from groundwork with multiple hospitals then switching to a local analysis of activity.

\section{The Surgical Suite terms}

A surgical suite (Fig. 1) is a "group of one or more ORs and adjunct facilities, such as a sterile storage area, scrub room, and recovery" [19]. The surgical suite is comprised of numerous equipment: to carry information (paper notes, medical records), to communicate (whiteboards, phone calls, text messages, emails), computers to access the hospital system and patient information. Surgical suites are dedicated to surgical patients' care and are overloaded with information, short deadlines (emergencies) and missing spatial organization.

The surgical suite staff is comprised of nurses, surgeons, anesthesiologists, board runners (who are also nurses), technicians, cleaning crew, and transporters.

Pre-operation defines the step within the patient's journey in the hospital when the patient is getting ready for surgery, the main actors are the nurses, the surgeons, and the anesthesiologists; post-operation defines the step from the end of the surgery to the moment the patient is back to his/her room or is leaving the hospital. The main actors are the Nurses.

The principle coordination tool within the surgical suite is the whiteboard (Fig. 2): this board is the place of all discussions and contains all the cases scheduled for the day for the surgical suite. It supports exchanges and reflections about the scheduling activity and is edited with latest updates/re-scheduling actions about the different cases. For instance: Patient A has been sent for surgery, now he is currently in room \#10 etc.; or procedure updates, for instance: Patient B procedure has started.

\section{Groundwork}

To build the foundation of our work, we interviewed (via phone calls or in-person meetings) 103 stakeholders who are involved with surgical suites in Texas, New Jersey, North Carolina, New York, Illinois and California and France in the fields of: medical/healthcare (hospital administrators, surgeons, anesthesiologists, nurses), 
accounting, consulting and engineering services. Of the 103 stakeholders, 27 worked at hospitals, 69 in industry with hospitals as customers, 5 for universities, 1 for the NSF, and 1 was a prior-to-surgery patient.

The purpose of this was to understand the bottlenecks within hospital management of surgical suites from multiple perspectives. Three main considerations for a desirable outcome came up:

1. Shortening the "turnover time" between cases to optimize OR schedule plans and to minimize staff overtime.

2. Streamlining the operation and improving awareness, safety, and efficiency during a surgery case.

3. Improving patient satisfaction and outcome due to an optimized time of the operation.

This groundwork set up our qualitative analysis about the needs within the surgical suite. We then quantified these delays.

\section{Analysis of a local activity in the surgical suite}

We studied a surgical suite of our home institution, since there is a correlation between the best electronic health support and the fact that it is designed according to the particularities of a place [20]. We conducted contextual inquiries and observations of the surgical suite [21], including photographic captures of the whiteboard [22], to better understand the surgical suite activity at our home institution. The practical results of these studies were the observations of significant and systematic reporting of the events occurring inside the OR onto the whiteboard - for instance, the average delay of 15 minutes per OR for the event "patient entry in the OR"; the fact that information sharing could be improved; and the more data that could be acquired if the whiteboard was electronic.

\section{Rationales}

As opposed to civil aviation traffic, there is no satisfying digital system in the hospital to track, in real-time, the progression of each surgery and map the overall state and traffic of a large surgical suite. The accumulation of delays in the surgical suite is critical because it leads to more case cancellations, stress for the staff and loss of revenue for the hospital which affects mostly the patients, and surgical suite awareness and communication problems are the main source of these delays - most of all on the turnover task [7, 21]. Each surgical suite has its own culture and rules, including social ones, and we must be careful to directly involve stakeholders in any system design process for such environment.

By taking in account the groundwork and environment analysis, our hypothesis is that by building a continuum of interfaces, using an iterative design process, and involving the surgical staff in participatory design sessions at every step will engage better collaboration awareness among the surgical suite, and therefore help reduce these delays (Fig. 3).

\section{The system}

\section{Architecture and computational framework of the system}

This work is carried out within the development of a cyber-infrastructure consisting of three elements [21] (Fig. 4):

1. SmartOR [21-25].

2. A continuum of interfaces described in the next sections.

3. A mathematical model of the surgical suite patient flow [7][26].

The SmartOR is a set of non-invasive sensors installed inside the OR and capture the surgery status - patient in/out of the OR, patient intubation/extubation, laparoscopic procedure start/end - and feeds it to the surgical suite database.

The mathematical model is an agent-based representation of the surgical suite organization and surgical staff collaboration that takes into account human behavior and performance in a complex system approach. The output of the model helps to understand the accumulation of delays within the surgical suite and to show that 
turnover time between surgeries, as defined as one of the most critical performance indicators, is the most nonlinear functional output of the system.

The stakeholders interact with this architecture by using the different interfaces as input terminals and visualization tools of the surgical suite state.

We present each step of that construction for each of the next parts of this section:

1. An ATC analogy.

2. Background: the context.

3. Actual: the current activity of the staff.

4. New: The activity that the new interfaces offer.

\section{OR status and the "flight status"}

Background: To manage the surgical flow, we need to acquire the real-time OR state.

Actual: Typically, OR state is acquired by physically going into the OR, or by calling the surgical staff inside the room. Because of the geographic distribution of the suite that may contain several dozen rooms, or the latency of phone communication and the interruptions generated, this does not represent the optimum method.

New: We designed a SmartOR setup based on a minimalist set of robust sensors (Fig. 5) that wirelessly communicates the OR state autonomously. This information can be posted in real time at the entrance of the OR with a simple tablet display, thereby removing the need to enter the room, which also has potential impact on airborne infection [27]. An alternative solution provided by the industry is to place RFID tags on each member of the staff but the acceptance of this technology by personnel is fairly low [28]. On the contrary, our solution targets events.

\section{Mapping the surgical suite state or "building a radar" for the Board Runner}

Background: The board runner is a nurse who is responsible for scheduling the cases within a surgical suite and optimizing the surgical flow.

Actual: The board runner receives information from Epic (the hospital system) and from nurses, surgeons, residents, etc. who manually enter information into Epic. The information appears on displays as lists.

New: We designed the control room interface to display the SmartOR information as a map that symbolically shows the surgical suite's status and allows the user to enter a request of information to the staff (Fig. 6 and Fig. 7). We verified with the board runners that a symbolic map display saves time and improves visual performance in obtaining the information at the surgical suite level [21]. The system can also be installed in the OR manager's office in order to prevent interruption of his/her daily duties.

\section{A shared board - OnBoard, to cadence surgical flow or the "control tower" of the surgical staff}

Background: The board runner and his/her team uses the traditional whiteboard to schedule/re-schedule the surgical cases throughout the day based on emergencies, requests, surgery requirements, delays, etc.

Actual: The board runner goes to the whiteboard (Fig. 2) to think about the best solution to optimize the flow, taking into account the unforeseen events cited above. He/She takes an eraser and a marker, and erases/writes new information so that the whole staff will be aware of it. Updates about OR status are sometimes manually input by nurses or other staff on the whiteboard. Anesthesiologists use the whiteboard for their own scheduling. Above the whiteboard are Epic screens, helping the staff with the schedule. The problem is that these screens are often shutdown or are displaying information that is not as up-to-date as it is on the whiteboard. Some usability problems can be found on these screens like the fact that many important elements are too small to read.

The whiteboard provides a natural and robust teamwork interface to manipulate individual OR states and prioritizes events the same way air-controllers manipulate paper strips for flights [29-30]. 
New: OnBoard is an electronic whiteboard whose purpose is to replace the traditional whiteboard of the surgical suite. The information displayed on OnBoard comes from the Epic database that is manually entered the night before. To transition smoothly from the traditional whiteboard of Fig. 2 to the interactive OnBoard, we used a multitouch display of approximately the same dimensions as the whiteboard (84 inches) that can hang on the wall the same way (Fig. 8) After a rigorous testing protocol, we decided to use a $4 \mathrm{~K}$ InGlass ${ }^{\mathrm{TM}}$ technology multitouch surface that provides for our users the best cost/performance ratio. OnBoard is a shared and large multi-user surface that allows the surgical suite staff to monitor the patient flow in the surgical suite. Most importantly the information entered by the staff on the interactive whiteboard can be tracked by the cyberphysical system.

\section{Engaging the social network of staff "just on time"}

Background: Epic contains the schedule planned the night before along with the EHR. It shows the status of the surgical suite as the board runner/nurses make their inputs throughout the day. These inputs are often delayed due to the high workload and critical activities. This information is available on Epic servers.

Actual: When the staff needs to exchange information and collaborate about case scheduling, they can go to the whiteboard and talk with the Board Runner or alternatively call/text message him/her.

New: We designed the mobile phone app (Fig. 9) to bring OnBoard information to the staff, out of the surgical suite. The mobile app is composed of a main page containing the list of all the cases the user is following. When the user touches a case he/she opens a detailed information page about the selected case.

The overall expansion of the system across the space and time built incrementally with these four steps is complex but needs to appear to the end user community as ubiquitous and natural as possible.

\section{Conclusion and Discussion}

Our approach was to treat the problem with an intricate adaptive system view [7, 31] and to encompass all the scales of communication and interaction with a continuum of interactions for avoiding gaps and broken links in the surgical work-flow. Our construction used a bottom-up approach by first acquiring OR statuses, mapping OR suite activity to make it visible, organizing a common place to engage collaboration that we called OnBoard, and finally overcoming space limitation by linking people via mobile devices. We learned from our user community how to balance the design of this continuum to circulate information between individual staff while preserving moment and place of collaboration. This continuum is tangible thanks to a cyber-infrastructure that is kept as little intrusive as possible to the hospital management system. Our iterative design cycle is adaptive as the hospital community continues to evolve with new technology and medical devices.

Further, our work highlighted three goals from the surgical suite community: shortening the "turnover time"; streamlining the operation by improving awareness, safety and efficiency; improving patient satisfaction and outcome.

With the continuum of interfaces presented in this article, the staff may have the tools to both preserve moments - dedicated to one patient - and save time in terms of scheduling, and to preserve common places for coordination and movement through the hospital space. According to the location of the interfaces, OR door/control room/surgical suite information hall/personal mobile phones, different notifications or visualizations must be taken into account. The importance of a notification can be different according to the moment: the board will notify the staff in a more invasive way that an OR is not ready to receive a patient right before this patient should actually enter the OR rather than an hour before. While we have sufficient user feedback and measurements [21-24] to claim that our system has the potential to improve the first two goals, we still have to incorporate the patient in our study. Patients' and families' engagement is a transformative force in the health industry, and insurance policy in the United States now has a component strictly dependent upon patient satisfaction that will keep growing in importance in the near future [32].

Short-term future work will consist of a full-scale clinical study of the system, i.e. OnBoard installed in the same suite as the SmartOR sensors and connected to the EHR system. We will then evaluate user experience with 
OnBoard. Long-term future work encompasses the expansion of the continuum of interactions to reach the patient and the family members who need to manage anxiety and be prepared.

\section{Acknowledgments}

We would like to thank the Dunn and OPC OR crew at Houston Methodist Hospital who actively participated in this study.

\section{Compliance with Ethical Standards}

After being reviewed by the Director of Office of Research Protections of the Houston Methodist Research Institute, this project was declared to not require either IRB or ARAF review.

\section{Funding}

This study was funded by National Science Foundation under the I/UCRC for Cyber-Physical Systems for the Hospital Operating Room Grant No.1657550.

\section{Conflict of interest}

Author Juliette Rambourg declares that she has no conflict of interest. Author Hélène Gaspard-Boulinc declares that she has no conflict of interest. Author Stéphane Conversy declares that he has no conflict of interest. Author Marc Garbey declares that he has no conflict of interest.

\section{Ethical Approval}

All procedures performed in studies involving human participants were in accordance with the ethical standards of the institutional and/or national research committee and with the 1964 Helsinki declaration and its later amendments or comparable ethical standards.

\section{Informed consent}

Informed consent was obtained from all individual participants included in the study.

\section{References}

1. HIMSS analytics Database (2015).

2. Cuschieri A (2006) Nature of human error: implications for surgical practice. Annals of surgery 244(5):642.

3. Erdogan SA, Denton BT (2011) Surgery planning and scheduling. Wiley Encyclopedia of operations research and management science.

4. Doryab A, Bardram JE. Designing activity-aware recommender systems for operating rooms (2011) InProceedings of the 2011 Workshop on Context-awareness in Retrieval and Recommendation pp. 43-46. ACM.

5. Bossen C, Foss M (2016) The collaborative work of hospital porters: accountability, visibility and configurations of work. InProceedings of the 19th ACM Conference on Computer-Supported Cooperative Work \& Social Computing pp. 965-979. ACM.

6. Bardram JE, Bossen C (2005) A web of coordinative artifacts: collaborative work at a hospital ward. InProceedings of the 2005 international ACM SIGGROUP conference on Supporting group work pp. 168176. ACM.

7. Garbey M, Joerger G, Rambourg J, Dunkin B, Bass B (2017) Multiscale Modeling of Surgical Flow in a Large Operating Room Suite: Understanding the Mechanism of Accumulation of Delays in Clinical Practice. Procedia Computer Science 108:1863-72.

8. Lee I, Sokolsky O, Chen S, Hatcliff J, Jee E, Kim B, King A, Mullen-Fortino M, Park S, Roederer A, Venkatasubramanian KK (2012) Challenges and research directions in medical cyber-physical systems. Proceedings of the IEEE 100(1):75-90. 
9. Haque SA, Aziz SM, Rahman M (2014) Review of cyber-physical system in healthcare. International Journal of Distributed Sensor Networks 10(4):217415.

10. Tang C, Carpendale S. Evaluating the deployment of a mobile technology in a hospital ward (2008) InProceedings of the 2008 ACM conference on Computer supported cooperative work pp. 205-214. ACM.

11. Moss J, Xiao Y, Zubaidah S (2002) The operating room charge nurse: coordinator and communicator. Journal of the American Medical Informatics Association 9(Supplement_6):S70-4.

12. Prgomet M, Georgiou A, Westbrook JI (2009) The impact of mobile handheld technology on hospital physicians' work practices and patient care: a systematic review. Journal of the American Medical Informatics Association 16(6):792-801.

13. Kusunoki D, Sarcevic A, Zhang Z, Yala M (2015) Sketching Awareness: A Participatory Study to Elicit Designs for Supporting Ad Hoc Emergency Medical Teamwork. Computer Supported Cooperative Work (CSCW) 24(1):1-38.

14. Bardram JE, Nørskov N (2008) A context-aware patient safety system for the operating room. InProceedings of the 10th international conference on Ubiquitous computing pp. 272-281. ACM.

15. Amir O, Grosz BJ, Gajos KZ, Swenson SM, Sanders LM (2015) From care plans to care coordination: Opportunities for computer support of teamwork in complex healthcare. InProceedings of the 33rd Annual ACM Conference on Human Factors in Computing Systems pp. 1419-1428. ACM.

16. Kapur N, Parand A, Soukup T, Reader T, Sevdalis N (2015) Aviation and healthcare: a comparative review with implications for patient safety. JRSM open 7(1):2054270415616548.

17. Toff NJ (2010) Human factors in anaesthesia: lessons from aviation. British journal of anaesthesia $105(1): 21-5$.

18. Helmreich RL (2000) On error management: lessons from aviation. Bmj 320(7237):781-5.

19. Surgical suite. (n.d.) Mosby's Medical Dictionary, 8th edition. (2009). Retrieved February 72018 from https://medical-dictionary.thefreedictionary.com/surgical+suite

20. Harrison S, Dourish P. Re-place-ing space: the roles of place and space in collaborative systems (1996) InProceedings of the 1996 ACM conference on Computer supported cooperative work pp. 67-76. ACM.

21. Joerger G, Rambourg J, Gaspard-Boulinc H, Conversy S, Bass B, Dunkin BJ, Garbey M (2017) A CyberPhysical System to Improve the Management of a Large Suite of Operating Rooms. ACM Transactions on Cyber-Physical Systems.

22. Joerger G, Rambourg J, Garbey M, Conversy S, Gaspard-Boulinc H (2017) Re-engineer operating room data acquisition and transmission for improving surgical suite awareness and management. InBiomedical \& Health Informatics (BHI), 2017 IEEE EMBS International Conference pp. 205-208. IEEE.

23. Garbey M, Joerger G, Huang A, Salmon R, Kim J, Sherman V, Dunkin B, Bass B (2015) An intelligent hospital operating room to improve patient health care. Journal of Computational Surgery 2(1):3.

24. Huang AY, Joerger G, Fikfak V, Salmon R, Dunkin BJ, Bass BL, Garbey M (2017) The SmartOR: a distributed sensor network to improve operating room efficiency. Surgical endoscopy 31(9):3590-5.

25. Huang AY, Joerger G, Salmon R, Dunkin B, Sherman V, Bass BL, Garbey M (2016) A robust and nonobtrusive automatic event tracking system for operating room management to improve patient care. Surgical endoscopy 30(8):3638-45.

26. Garbey M, Joerger G, Rambourg R, Dunkin B, Bass L. B (2018) Multiscale Modeling of Surgical Flow Explains Lognormal Distribution of Surgical Time and Occurrence of Large Delays, PLOS ONE, Under revision.

27. Villafruela JM, San José JF, Castro F, Zarzuelo A (2016) Airflow patterns through a sliding door during opening and foot traffic in operating rooms. Building and Environment 109:190-8. 
28. Yao W, Chu CH, Li Z (2010) The use of RFID in healthcare: Benefits and barriers. InRFID-Technology and Applications (RFID-TA), 2010 IEEE International Conference pp. 128-134. IEEE.

29. Conversy S, Lemort A, Valès S. MAMMI WP1: Review of existing systems (2007) Technical report, T06043, Eurocontrol.

30. Conversy S, Gaspard-Boulinc H, Chatty S, Valès S, Dupré C, Ollagnon C (2011) Supporting air traffic control collaboration with a TableTop system. InProceedings of the ACM 2011 conference on Computer supported cooperative work pp. 425-434. ACM.

31. Miller JH, Page SE (2009) Complex adaptive systems: an introduction to computational models of social life: an introduction to computational models of social life. Princeton university press.

32. Burns KK, Bellows M, Eigenseher C, Gallivan J (2014) 'Practical'resources to support patient and family engagement in healthcare decisions: a scoping review. BMC health services research 14(1):175.

\section{Figures Captions}

Fig 1 Surgical suite example of architecture. The physical organization of the different rooms makes the sharing of information difficult by nature, as the distance does not favor communication. On this image we can also see that the case scheduling traditional whiteboard is centralized most of the time and is located nearby the control room.

Fig 2 Surgical suite whiteboard. As the central element of communication and exchanges about the case scheduling activity among the surgical staff, it contains all the scheduling of the day (written in black) as well as additional info such as equipment and staff allocations. We can also see on the image the additional updates made in color (red, sometimes blue), to alert on specific matters, such as an emergency case entering the flow.

Fig 3 Design methods for the continuum expansion. Through participatory and iterative design with the end-users, we progressively developed component of the continuum of interfaces to fill the gap created by the distances within the surgical suite (Operating Room door to the Control Room, a staff location to the Control Room etc.).

Fig 4 Representation of the cyber-infrastructure. The SmartOR sensors collect OR state data and save it in the database (a). The different interfaces (OnBoard, Mobile phone application and Control Room interface) can then dispatch it through the surgical suite (b, c, d). OnBoard is also considered a sensor as what is written on it or the modifications made on it can be also saved in the database (b). The mathematical model runs data to create a better understanding of the flow and potentially send alerts/help to re-schedule cases.

Fig 5 Analogy between a radar in civil aviation and for the surgical suite. Just like a flight as a route and a status, we seek to build the radar of the surgical suite to assess better its status. With more up-to-date data and better collaboration tools, the staff could anticipate better and reduce stress and delays.

Fig 6: Analogy between an air traffic controller and a control room board runner. The board runner runs the surgical suite, he/she constantly has its status in the mind. He/she is responsible for the smooth running of operations. This image shows how new technology can empower the board runner to monitor the surgical suite more efficiently.

Fig 7 Control room user interface. This prototype shows how a surgical suite map can help the board runner to monitor the surgical suite status. The map reduces the problem of distance in the surgical suite between the different rooms by giving with colors a resume of the global status of each rooms, surgeons and patients. We also considered that a board runner could be interested in looking the surgical suite status of other surgical suites of the hospital, to potentially exchange patients and improve efficiency.

Fig 8 OnBoard interface. This large multitouch screen is destined to replace the traditional whiteboard. Its layout is built to copy the traditional whiteboard, and by adding more features. The main power of such an interface compare to the whiteboard is the traceability of changes.

Fig 9 Main layout of the mobile phone app. This image shows the main layout of the mobile phone application: a resume of the cases that the user can follow on his/her phone anywhere with an access to the hospital intranet. This allow us to dispatch information in a wider area than only the surgical suite if needed. 


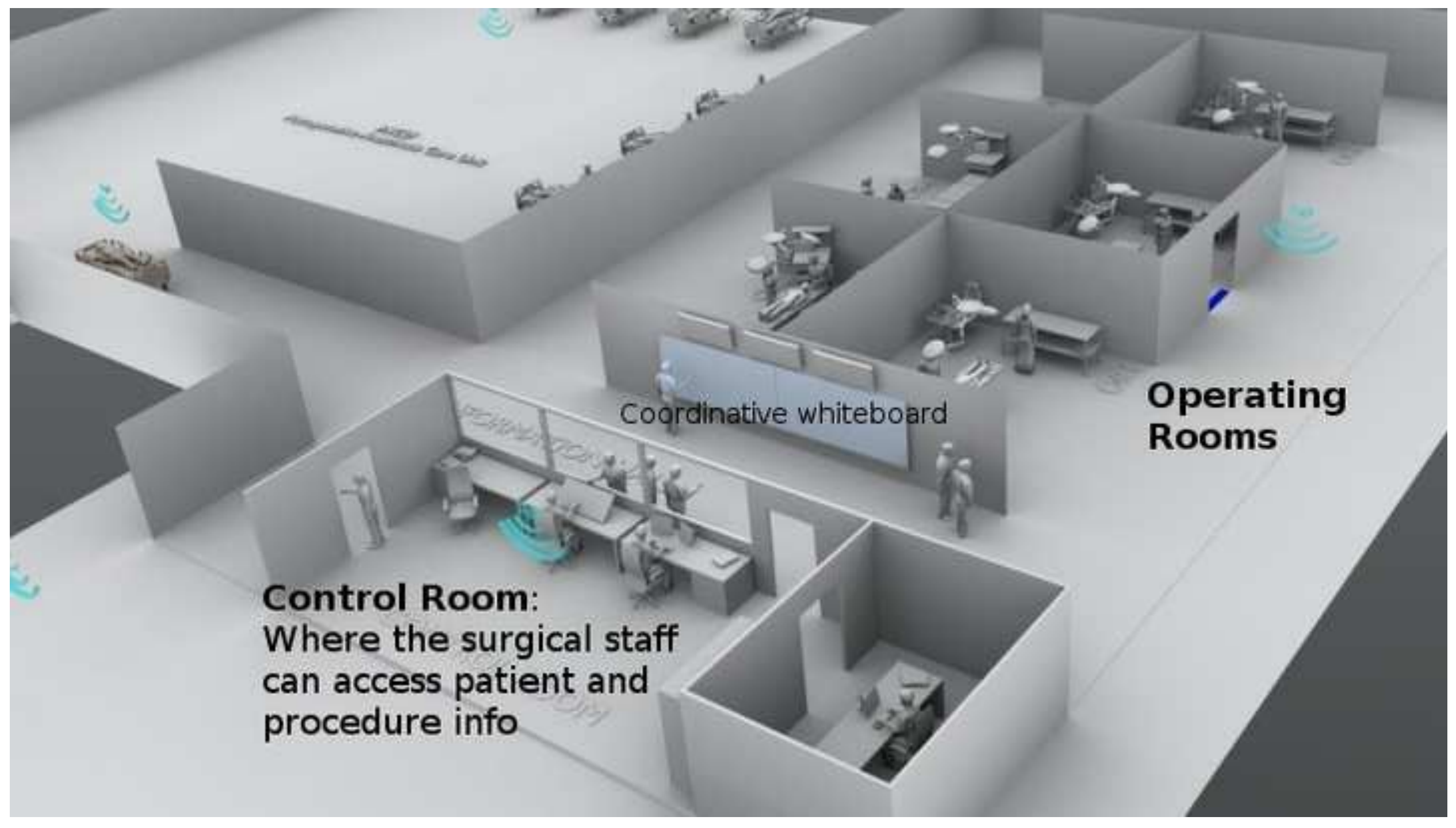




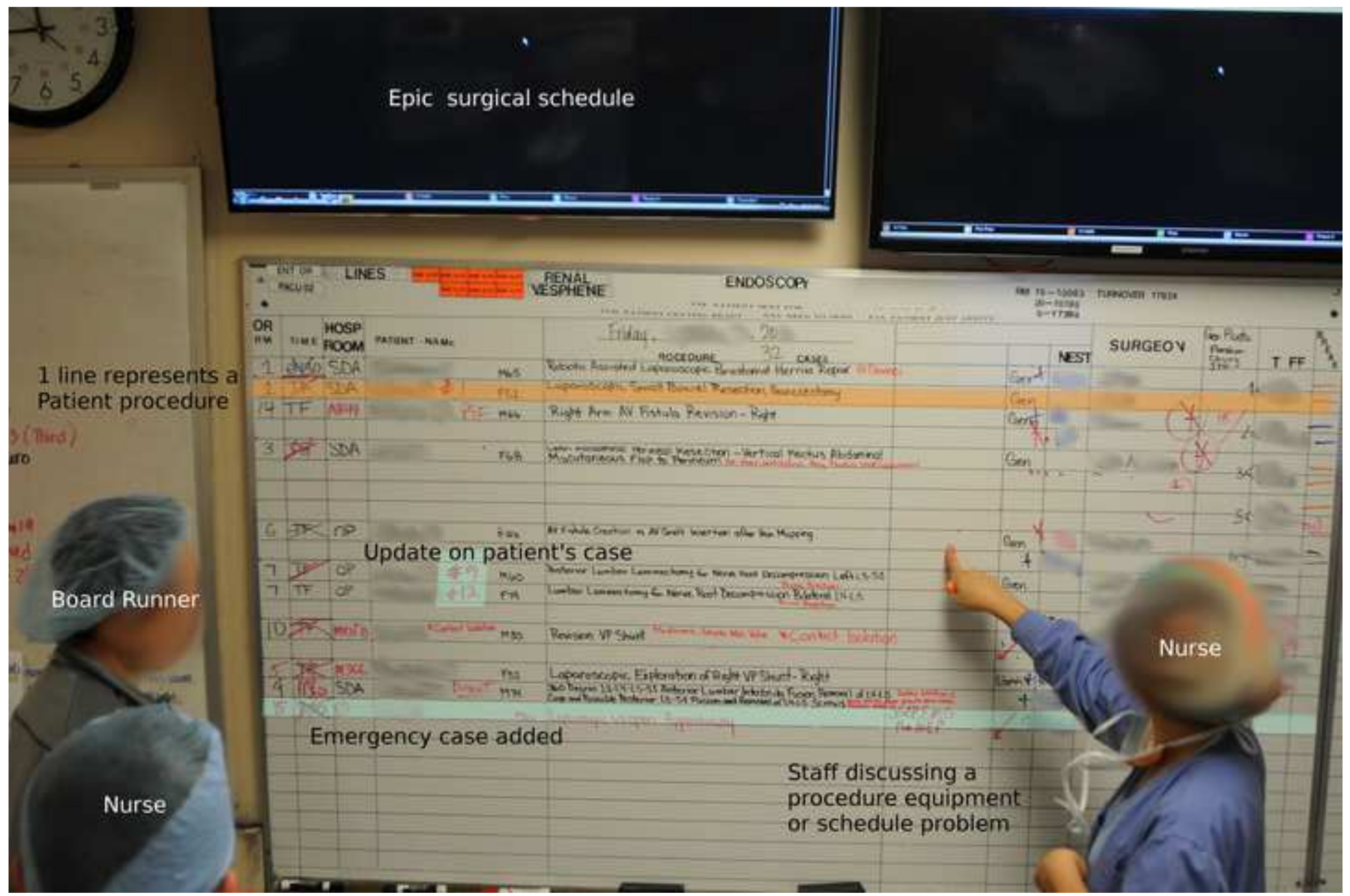

Staff discussing a

. 


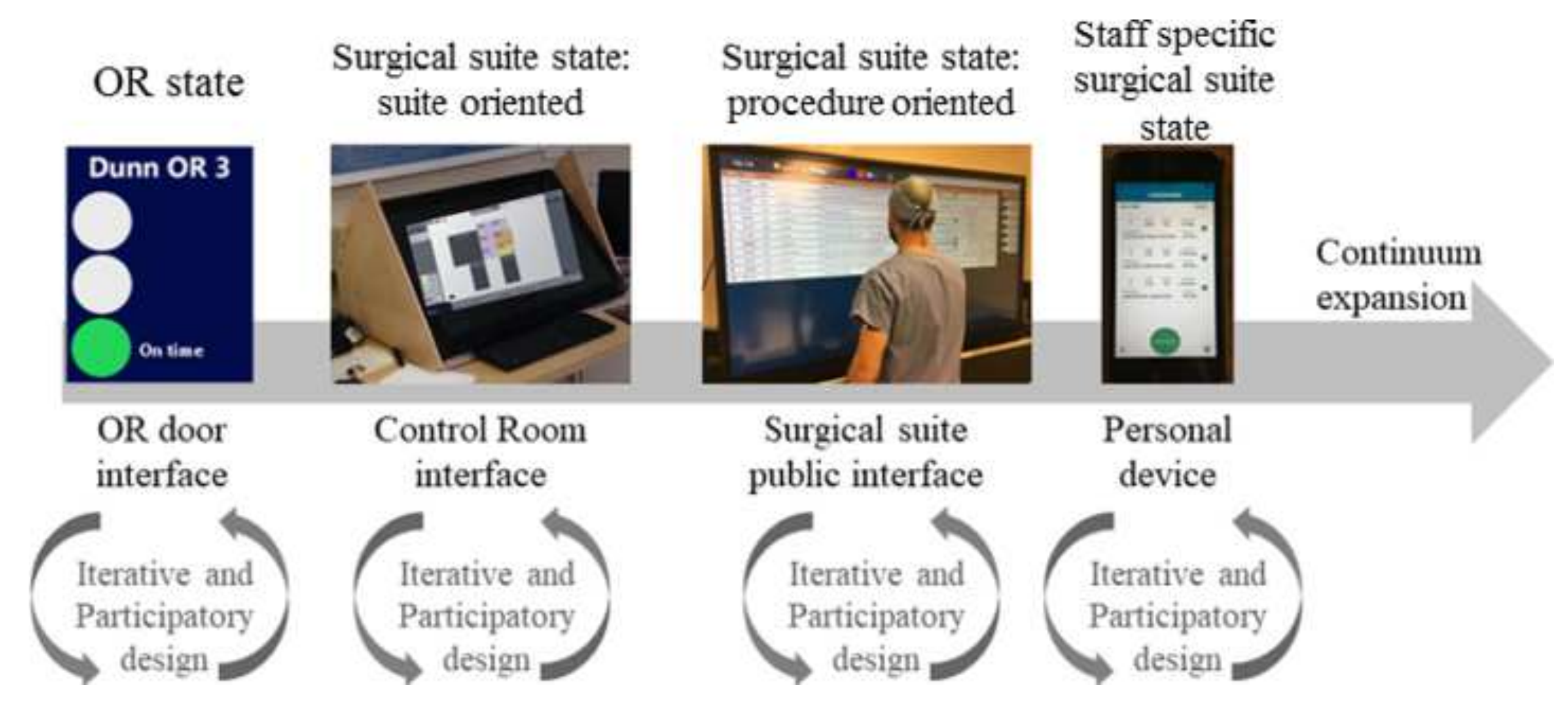

Continuum expansion
Iterative and ticipatory
Surgical suite state: procedure oriented

\section{Control Room} interface

(1)

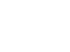

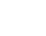

.

.

. 


\section{e)

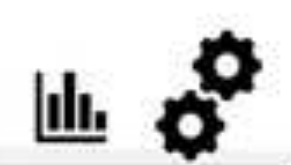

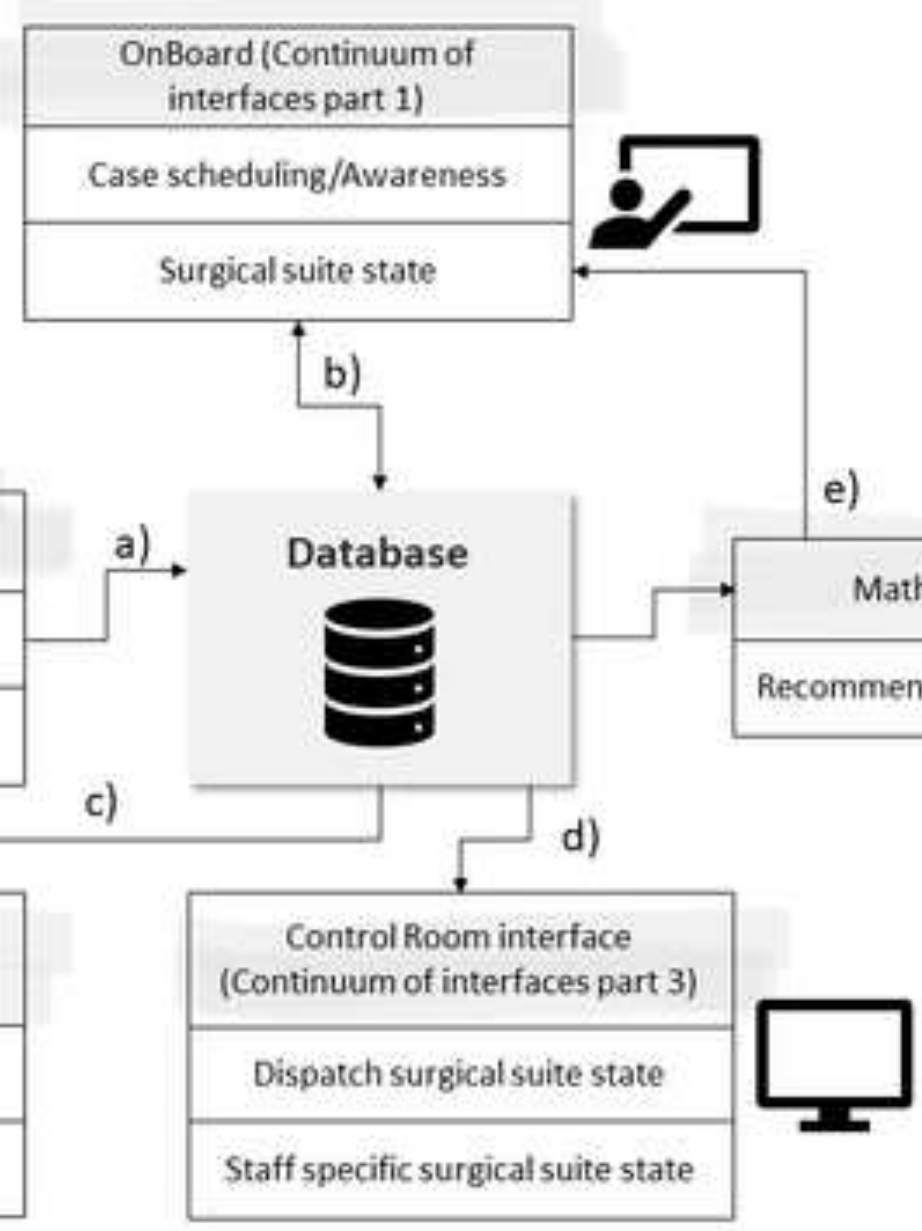

thematical model

Legend
\begin{tabular}{|c|}
\hline Technology title \\
\hline Function of the technology \\
\hline State indicator \\
\hline
\end{tabular}

Staff Mobile Phone Application (Continuum of interfaces part 2)

Dispatch surgical suite state

Staff specific surgical suite state $\square$

\begin{tabular}{|c|}
\hline SmartoR \\
\hline OR state acquisition \\
\hline OR state \\
\hline
\end{tabular}

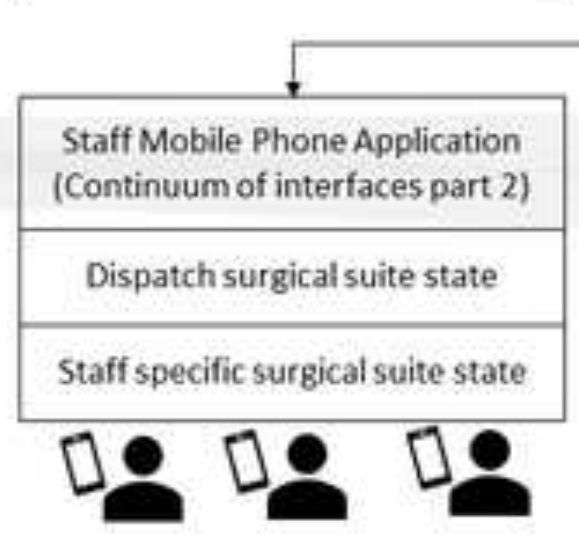

State indicator 


\section{SURGERY}

\section{CIVIL AVIATION}
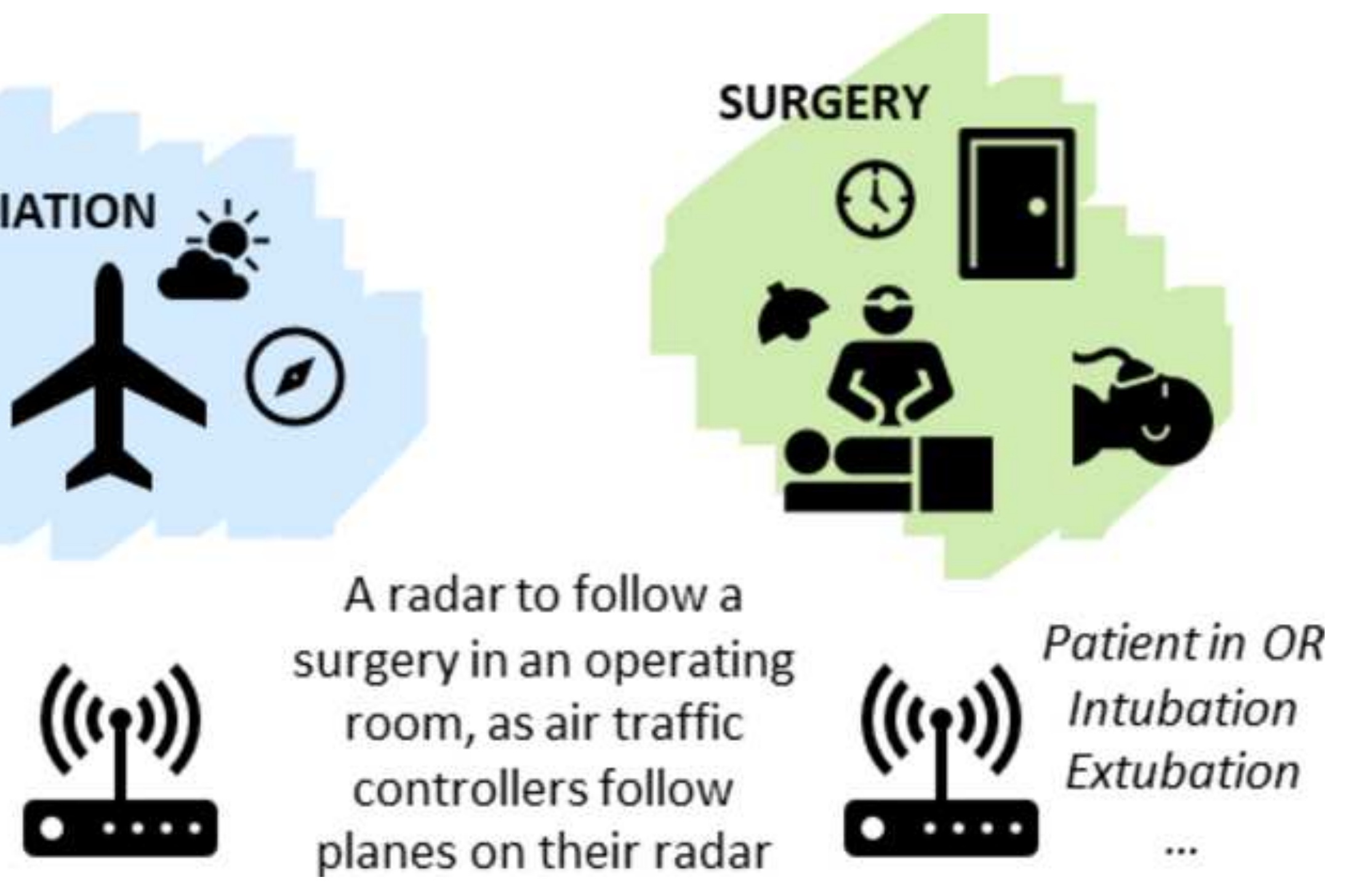

A radar to follow a

Location Altitude Weather

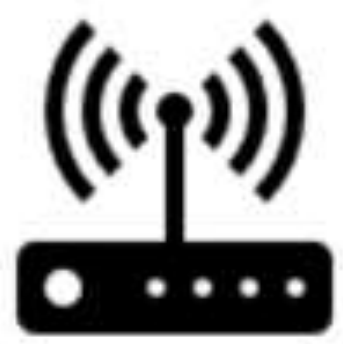
... surgery in an operating room, as air traffic controllers follow planes on their radar
Patient in $O R$ Intubation Extubation

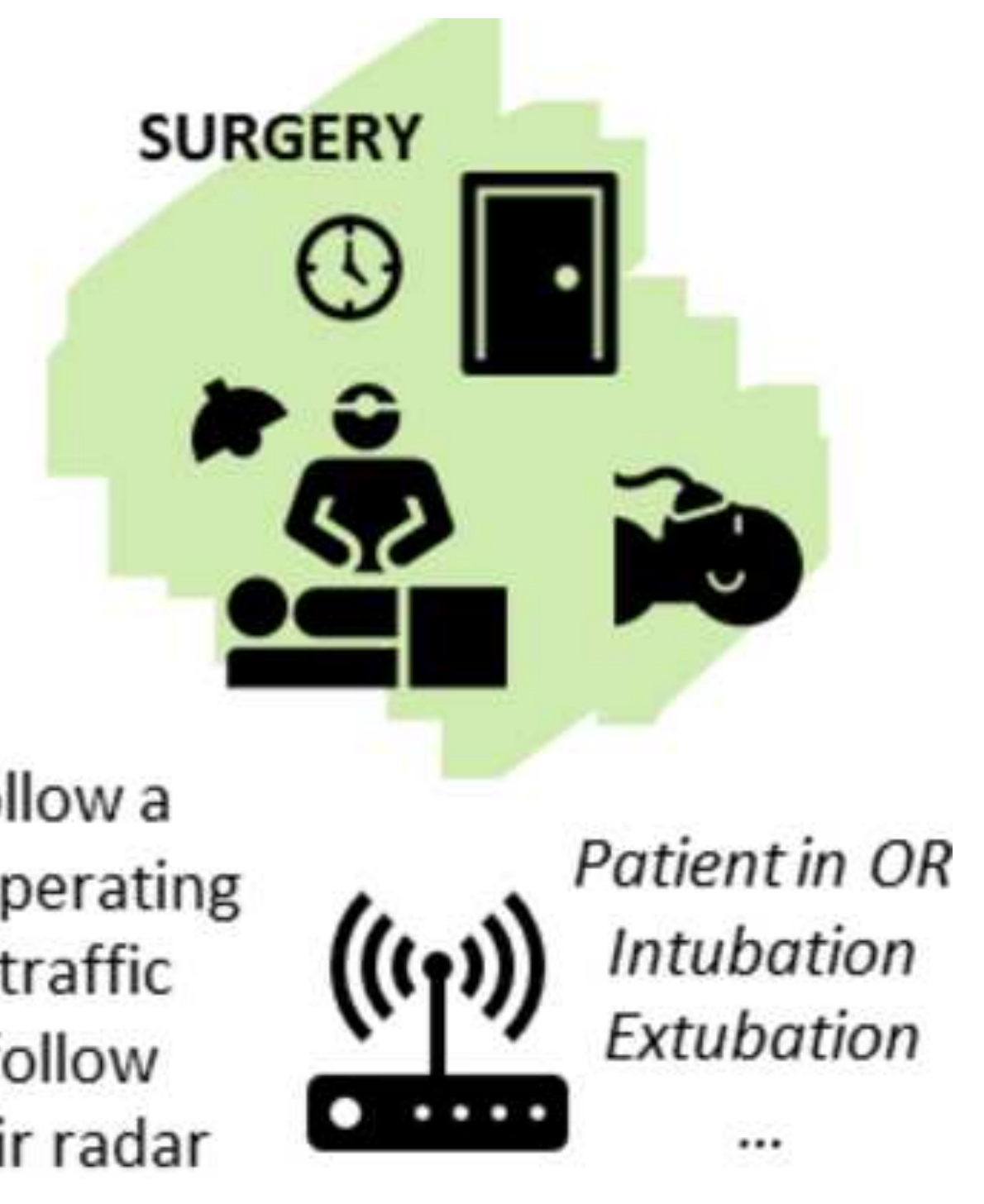

$$
\text { . }
$$




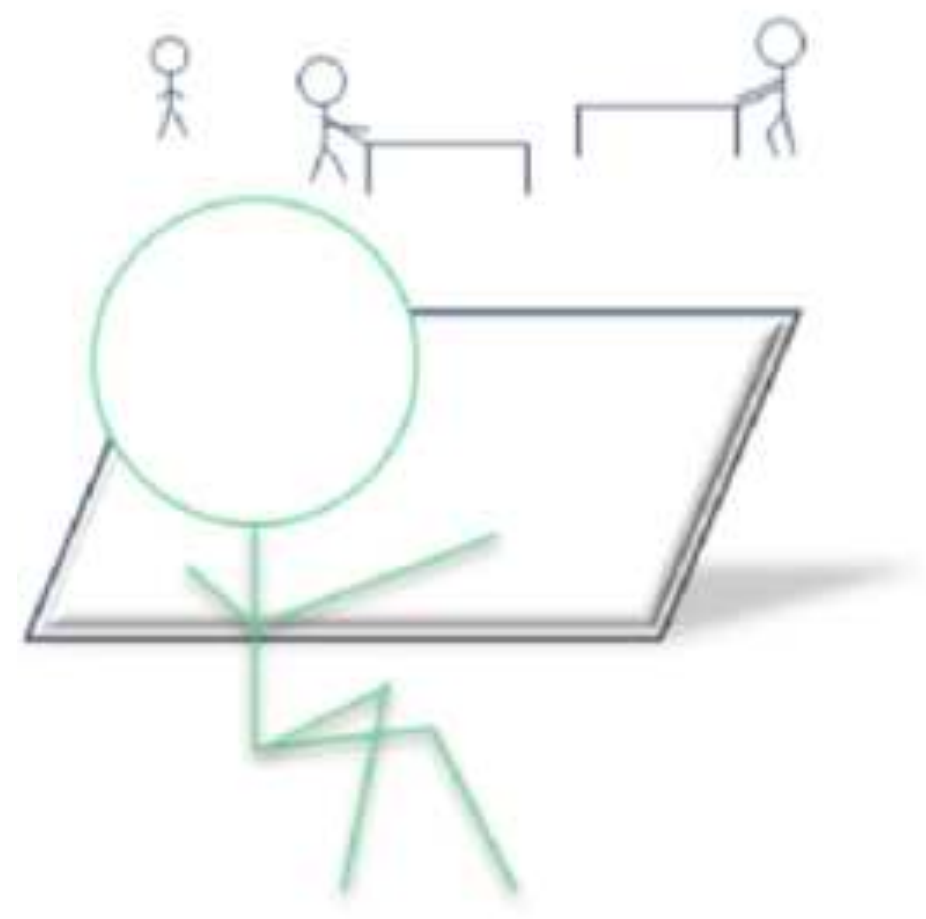

\section{Monitoring}

nurse
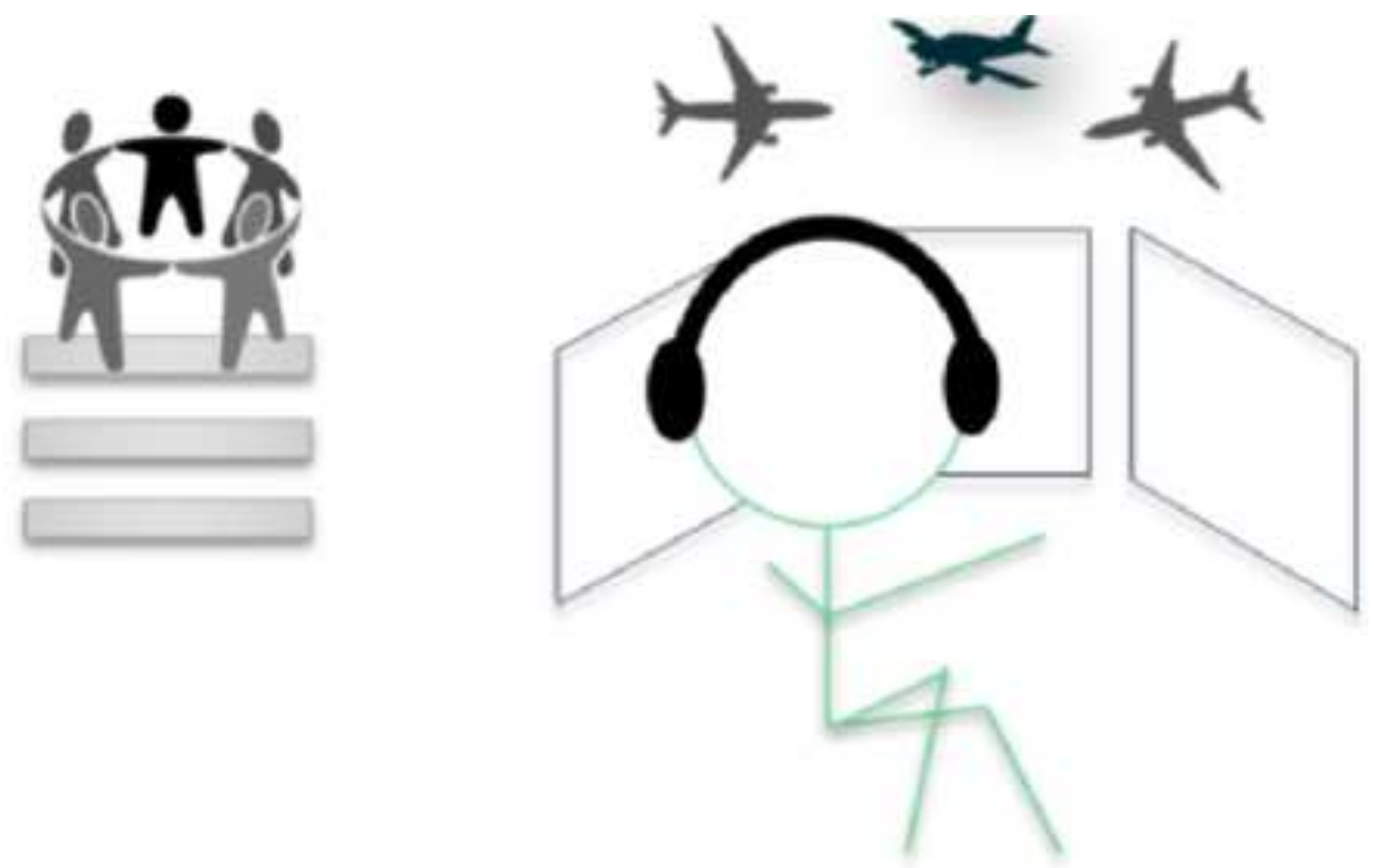

\author{
Air traffic \\ controller
}




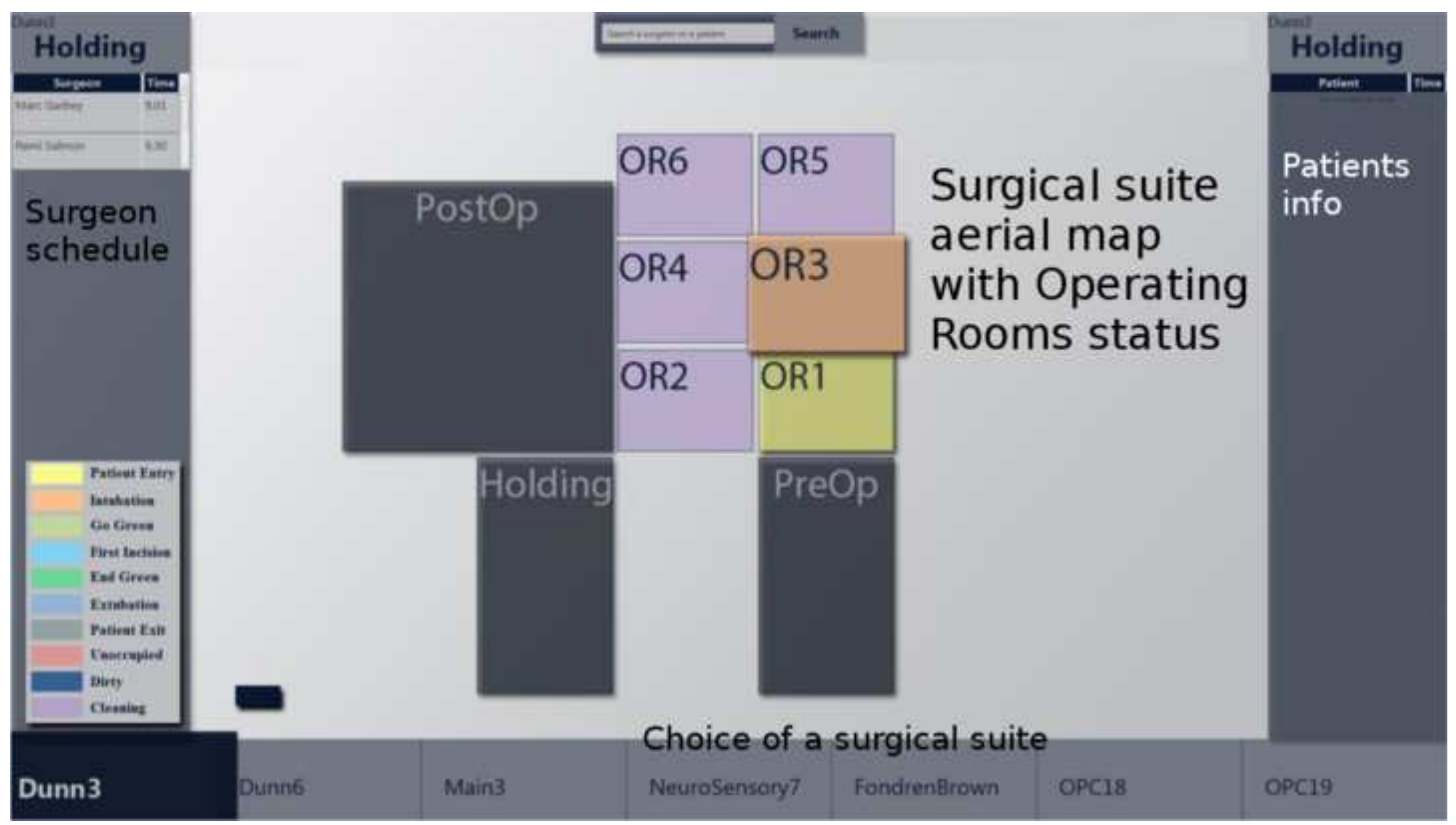




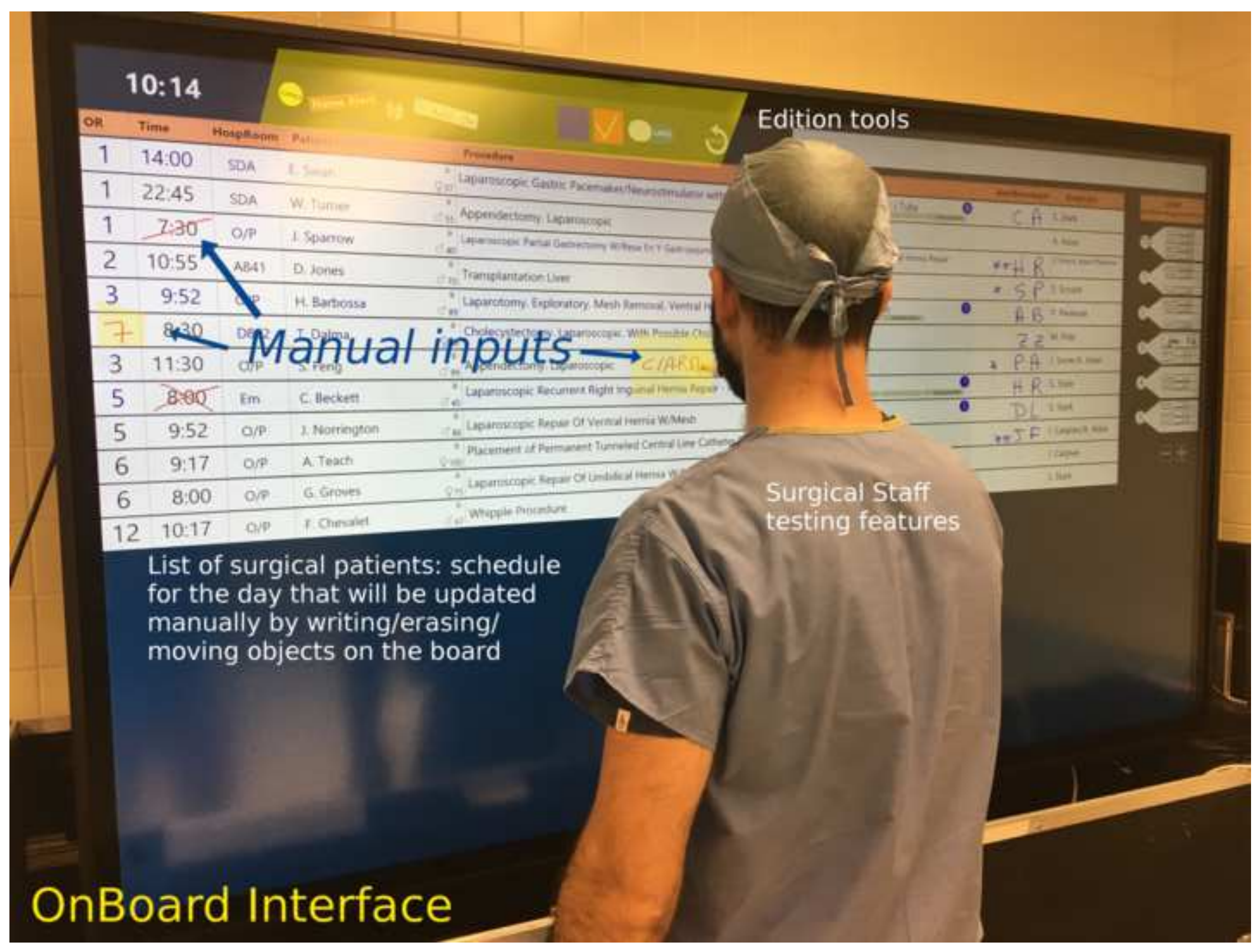


Mobile phone app Main View: list of cases the person is connected to

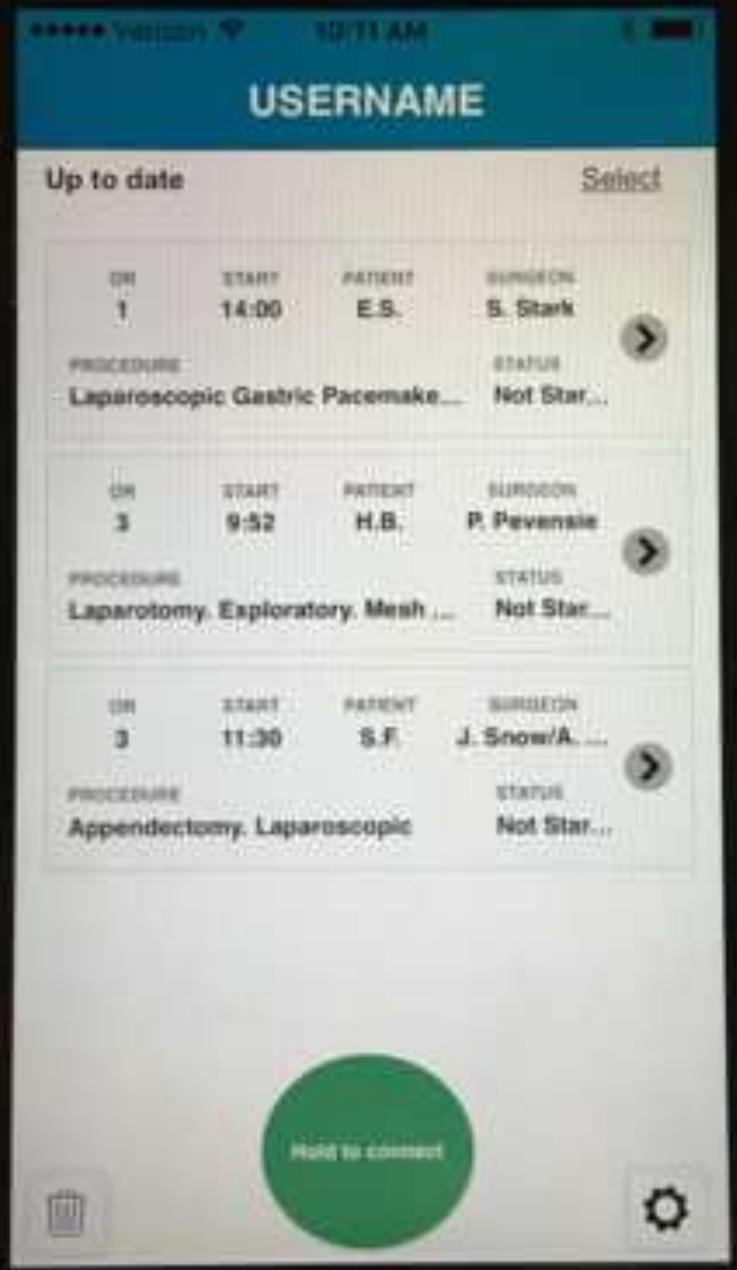

View when the user view the modification of a case

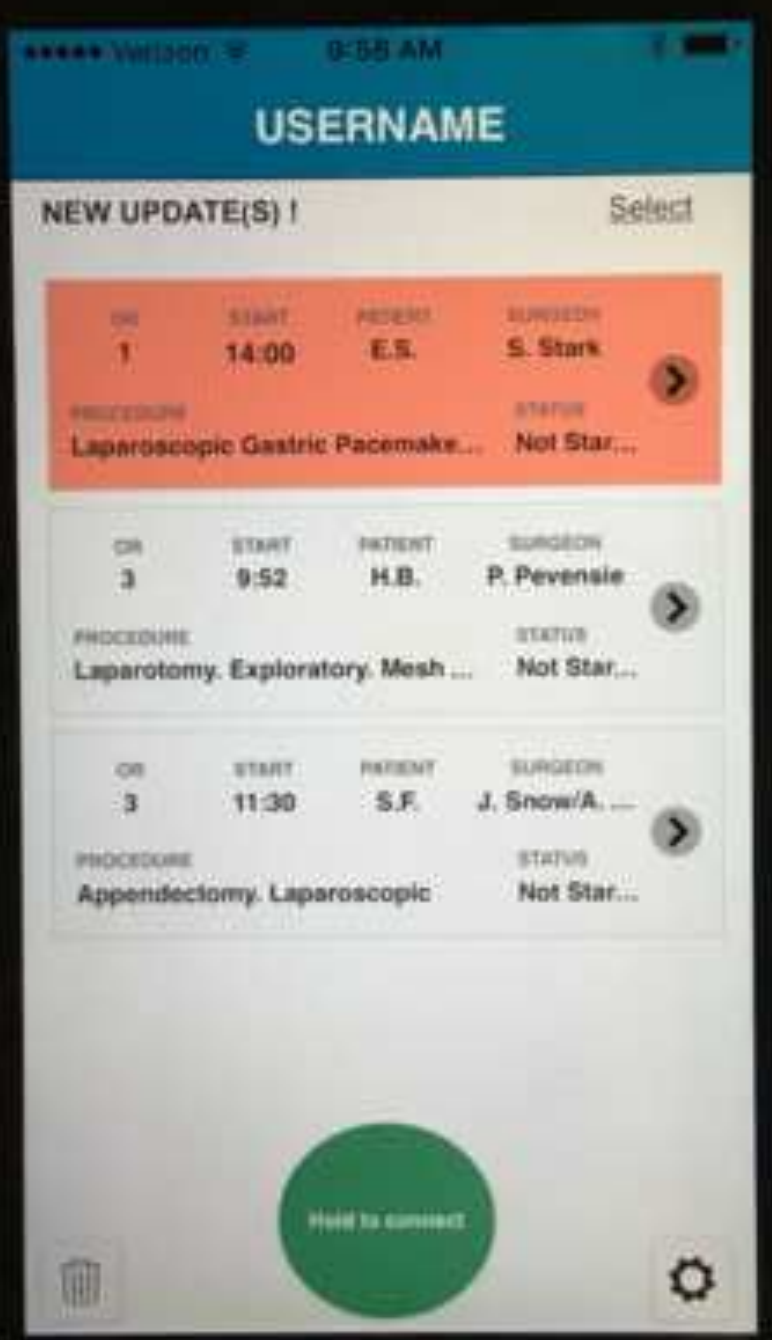

